\title{
Increased bone formation by prevention of osteoblast apoptosis with parathyroid hormone
}

\author{
Robert L. Jilka, Robert S. Weinstein, Teresita Bellido, Paula Roberson, \\ A. Michael Parfitt, and Stavros C. Manolagas
}

Division of Endocrinology and Metabolism, UAMS Center for Osteoporosis and Metabolic Bone Diseases, and Central Arkansas Veterans Health Care System, University of Arkansas for Medical Sciences, Little Rock, Arkansas 72205, USA

Address correspondence to: Robert L. Jilka, University of Arkansas for Medical Sciences, Division of Endocrinology and Metabolism, Slot 587, 4301 W. Markham, Little Rock, Arkansas 72205, USA.

Phone: (501) 686-7896; Fax: (501) 686-8954; E-mail: rljilka@life.uams.edu.

Received for publication February 19, 1999, and accepted in revised form July 12, 1999.

\begin{abstract}
The mass of regenerating tissues, such as bone, is critically dependent on the number of executive cells, which in turn is determined by the rate of replication of progenitors and the life-span of mature cells, reflecting the timing of death by apoptosis. Bone mass can be increased by intermittent parathyroid hormone (PTH) administration, but the mechanism of this phenomenon has remained unknown. We report that daily PTH injections in mice with either normal bone mass or osteopenia due to defective osteoblastogenesis increased bone formation without affecting the generation of new osteoblasts. Instead, PTH increased the life-span of mature osteoblasts by preventing their apoptosis - the fate of the majority of these cells under normal conditions. The antiapoptotic effect of PTH was sufficient to account for the increase in bone mass, and was confirmed in vitro using rodent and human osteoblasts and osteocytes. This evidence provides proof of the basic principle that the work performed by a cell population can be increased by suppression of apoptosis. Moreover, it suggests novel pharmacotherapeutic strategies for osteoporosis and, perhaps, other pathologic conditions in which tissue mass diminution has compromised functional integrity.
\end{abstract}

J. Clin. Invest. 104:439-446 (1999).

\section{Introduction}

The adult human skeleton is continually renewed by temporary anatomic structures comprising teams of juxtaposed osteoclasts and osteoblasts - 2 specialized cell types that originate from progenitors residing in the bone marrow. Orderly supply of osteoclasts and osteoblasts is evidently essential for skeletal homeostasis, as changes in their number are largely responsible for the mismatch between bone formation and resorption that underlies most systemic or localized bone diseases, including osteoporosis (1-4).

While several agents are capable of decreasing bone resorption and halting further bone loss in osteopenic states, the ideal drug would be an anabolic agent that increases bone mass by rebuilding bone. It is well established that daily injections of low doses of parathyroid hormone (PTH), an agent better known for its role in calcium homeostasis, increase bone mass in animals and humans (5-11), as does the PTH-related protein (PTHrP), the only other known ligand of the PTH receptor $(12,13)$. The mechanism of this anabolic effect, however, has not been established. Heretofore, it was widely believed that the anabolic effect of PTH was the result of increased osteoblast differentiation (5).

The rate of bone formation is largely determined by the number of osteoblasts (14), which in turn is determined by the rate of replication of progenitors and the life-span of mature cells, reflecting the timing of death by apoptosis. Because of evidence that apoptosis is the fate of the majority of osteoblasts (15), changes in the prevalence of osteoblast apoptosis should alter the rate of bone formation. Here it is shown that the increased osteoblast number, bone formation rate, and bone mass caused by intermittent administration of PTH to mice with either normal or reduced osteoblastogenesis is due to an antiapoptotic effect of the hormone on osteoblasts.

\section{Methods}

Mice. Four- to 5-month-old male or female SAMR1 and SAMP6 mice were from a colony established from breeders provided by Toshio Takeda (Kyoto University, Kyoto, Japan). Mice were maintained and used in accordance with National Institutes of Health (NIH) guidelines on the care and use of laboratory animals. Individual mice were electronically tagged at weaning (BioMedic Data Systems Inc., Seaford, Delaware, USA) and were fed a standard rodent diet (Agway RMH 3000; Amersham Life Sciences Inc., Arlington Heights, Illinois, USA) ad libitum. To examine the effect of PTH on bones, the mice were given daily subcutaneous injections of vehicle $(0.9 \%$ saline, $0.01 \mathrm{mM} \beta$-mercaptoethanol, $0.1 \mathrm{mM}$ acetic acid) or $400 \mathrm{ng} / \mathrm{g}$ body weight of hPTH(1-34) (Bachem California, Torrance, California, USA) dissolved in vehicle. Determination of bone mineral density. The bone mineral density (BMD) of the spine and hindquarters was determined by dual-energy x-ray absorptiometry (QDR 2000 Plus; Hologic Inc., Bedford, Massachusetts, USA) as described previously (3). Before the experiment began, BMD determinations were performed at 2-week intervals to identify the peak adult bone mass in order to ensure 
that effects of PTH would be assessed in the nongrowing skeleton. The evaluation of each scan was based on the exact positioning and placement of the region of interest on the baseline scan using the "Compare" technique $(3,4)$.

Determination of osteoblast progenitors. Femoral marrow cells from each animal were cultured separately at $2.5 \times$ $10^{6}$ cells per $10-\mathrm{cm}^{2}$ well and maintained for 28 days in phenol red-free $\alpha$-MEM containing $15 \%$ preselected FBS (HyClone Laboratories, Logan, Utah, USA) and 1 mM ascorbate-2-phosphate (16). Von Kossa's method was used to identify and enumerate colonies containing mineralized bone matrix, which were designated CFU-osteoblast (CFU-OB) colonies. Because each colony is derived from a single osteoblast progenitor, the number of CFU-OB colonies reflects the number of mesenchymal progenitors present in the original bone marrow isolate that are capable of differentiating into osteoblasts $(16,17)$.

Histomorphometry. Measurements of the femoral length and the midshaft diaphyseal cortical width were made with a digital caliper at a resolution of $0.01 \mathrm{~mm}$ (Mitutoyo model 500-196; Ace Tools, Fort Smith, Arkansas, USA). Histomorphometric examination of $5-\mu \mathrm{m}$-thick bone sections was performed using a computer and digitizer tablet (Osteomeasure Version 3.00; Osteometrics Inc., Atlanta, Georgia, USA) interfaced to a Zeiss Axioscope (Carl Zeiss Inc., Thornwood, New York, USA) with a drawing tube attachment $(4,18)$. Measurements were confined to the secondary spongiosa of the distal femur to ensure that only remodeling sites were analyzed. The terminology and units used are those recommended by the Histomorphometry Nomenclature Committee of the American Society for Bone and Mineral Research (19). The rate of bone formation $\left(\mu \mathrm{m}^{2} / \mu \mathrm{m} / \mathrm{d}\right)$ was calculated from the extent of bone surface labeled with tetracycline (viewed using epifluorescence) and the distance between the labels in areas where 2 labels are present. Osteoid was recognized by its distinct characteristics when stained with toluidine blue, and osteoblasts were identified as plump cuboidal cells with a perinuclear clear zone on osteoid surfaces. Wall width represents the amount of bone synthesized by a team of osteoblasts, and was measured as the distance from the quiescent bone surface to a cement line in the underlying bone demarcating the site at which bone formation began (4, 18). Cement lines used in wall-width measurements were curvilinear or scalloped and reached the quiescent cancellous surface. The existence of new packets of bone abutting old ones at the cement lines was verified using polarized light to see the different orientation of the lamellae in the packets. These features distinguish the cement lines from straight or evenly curved arrest lines, which are always parallel to the collagen lamellae, are thicker than the cement line, and never reach the surface (20). Osteocytes were identified inside lacunae in mineralized bone. Osteoclasts were recognized by staining with tartrate-resistant acid phosphatase (3).

Determination of apoptotic osteoblasts and osteocytes in vivo. Apoptotic osteoblasts were detected in sections of nondecalcified vertebral bone by the terminal deoxynucleotidyl transferase-mediated nick end labeling (TUNEL) reaction using reagents from Oncogene
Research Products (Cambridge, Massachusetts, USA) as previously described (4), with the following modifications. Sections were heated in a microwave oven in $0.1 \mathrm{M}$ citrate ( $\mathrm{pH}$ 6.0) for 4 minutes at $45^{\circ} \mathrm{C}$, incubated in $0.5 \%$ pepsin in $0.1 \mathrm{~N} \mathrm{HCl}$ for 20 minutes at $37^{\circ} \mathrm{C}$, rinsed with TBS buffer containing $2 \%$ BSA, and then incubated with Klenow terminal deoxynucleotidyl transferase and biotinylated dUTP. After repeated rinses in buffer, sections were incubated with streptavidin-horseradish peroxidase conjugate and subsequently incubated with diaminobenzidine. To improve the sensitivity of the reaction, sections were then incubated for 1-2 minutes with $0.15 \% \mathrm{CuSO}_{4}$ in $0.9 \% \mathrm{NaCl}(21,22)$. TUNEL-positive hypertrophic chondrocytes were observed at the lateral margins of the growth plates, serving as an internal positive control for each bone section. In each TUNEL-labeling assay, plastic-embedded sections of weaned rat mammary tissue were used as a positive control. Negative controls were made by omitting the transferase.

Cultured cells. Osteoblastic cells were isolated from calvariae of 3- to 6 -day-old C57BL/ 6 mice by sequential collagenase digestion (23); cultured for 5-8 days in $\alpha$ MEM (GIBCO-BRL, Grand Island, New York, USA) supplemented with 10\% FBS (Sigma Chemical Co., St. Louis, Missouri, USA); and frozen in liquid $\mathrm{N}_{2}$ until used. Murine osteocyte-like MLO-Y4 cells (provided by L. Bonewald, University of Texas Health Science Center at San Antonio, San Antonio, Texas, USA) were transduced with the pLXSN retroviral vector containing a construct encoding enhanced green fluorescent protein (EGFP) (CLONTECH Laboratories Inc., Palo Alto, California, USA) with the SV-40 large T antigen nuclearlocalization sequence attached to the $\mathrm{COOH}$-terminus (24). The construct was prepared by C.A. O'Brien (University of Arkansas for Medical Sciences, Little Rock, Arkansas, USA). Stably transduced cells were selected for neomycin resistance using G418 (Sigma Chemical Co.). MLO-Y4 cells were cultured on collagen-coated plates in $\alpha$-MEM supplemented with 5\% FBS and $5 \%$ bovine calf serum. Murine osteoblastic MC3T3-E1 cells and human osteoblastic MG-63 cells were cultured as previously described (15).

Determination of osteoblast and osteocyte apoptosis in vitro. The pyknotic fragmented nuclei typical of apoptotic cells were viewed using HOECHST 33258 fluorescent dye (Polysciences Inc., Warrington, Pennsylvania, USA), at a concentration of $1 \mu \mathrm{g} / \mathrm{mL}$ in $0.5 \mathrm{M} \mathrm{NaCl}, 10 \mathrm{mM}$ Tris-HCl, 1 mM EDTA ( $\mathrm{pH} 7.4$ ) in osteoblastic calvaria cells, and by EGFP fluorescence in MLO-Y4 osteocytes. Trypan blue staining ( $0.1 \%$ final concentration) was used for routine quantification of apoptosis (15). Briefly, nonadherent cells were combined with adherent cells released from the culture dish with trypsin-EDTA, centrifuged, and resuspended in PBS. The percentage of cells exhibiting both nuclear and cytoplasmic staining was determined using a hemocytometer. Previous findings indicated that the percentage of apoptotic cells determined by trypan blue staining corresponded to that determined by TUNEL staining (15). Using a recently described double-labeling procedure (25), we have also established that more than $90 \%$ of trypan blue-stained cells also exhibited red TUNEL labeling using NovaRed (Vector Laboratories, Burlingame, Cali- 
fornia, USA) as peroxidase substrate in cell cultures treated with TNF, dexamethasone, or etoposide to induce apoptosis (data not shown).

Statistics. Statistical analyses were performed using SAS software (SAS Institute Inc., Cary, North Carolina, USA) or SigmaStat (SPSS Science, Chicago, Illinois, USA). Unless otherwise indicated, data were analyzed by $t$ test or ANOVA after establishing normal distribution of data and homogeneity of variances. For longitudinal analysis of the effect of PTH on BMD, a mixed-effects longitudinal ANOVA model was used to allow specification of the covariance structure.

ANOVA could not be used to analyze the prevalence of apoptosis in vivo because of the low frequency of apoptotic cells and the heterogeneity of variance inherent in such proportional data. Therefore, exact logistic regression (LogXact; Cytel Corp., Cambridge, Massachusetts, USA) was used to analyze data when apoptotic cell counts from several animals were combined. The Grizzle-Starmer-Koch (GSK) categorical general linear regression model (26) was used to analyze data when apoptotic cell counts from each animal were measured. This method uses a weighted least squares approach to evaluate the variability of apoptosis prevalence among animals within groups, as compared with the variability between experimental groups (similar to ANOVA), and accounts for the variance structure of the categorical data. For these reasons, it is well suited for analysis of rare events. Because some bone sections contained no apoptotic cells, 0.5 was added to every frequency count to permit use of this procedure. This is a commonly used technique for handling the computational difficulties posed by sampling zeros (27).

\section{Results}

Daily subcutaneous injections of $400 \mathrm{ng} / \mathrm{g}$ of human $\mathrm{PTH}(1-34)$ [hPTH(1-34)] over a 4-week period progressively increased BMD in adult mice with normal bone mass (SAMR1) or in mice with osteopenia (3) due to impaired osteoblastogenesis and decreased bone forma- tion (SAMP6) (Figure 1a). This effect was greater in the hindlimbs than in the spine (not shown) and did not involve bone growth, as reflected by the lack of change in the length of the femur or its width at the diaphysis (Table 1). Remarkably, the increase in BMD was similar in the 2 strains, even though the baseline values were different (Figure 1b).

Consistent with the BMD increase, histomorphometric analysis of sections of cancellous bone from the distal femurs of mice of either strain treated with PTH showed increased cancellous bone area that correlated with the increased hindlimb BMD $(r=0.53$; $P<0.001)$. The latter could be explained by the increase in the number of osteoblasts covering the bone surface and by the increased rate of bone formation (Table 1). As expected from these changes, the amount of osteoid (the matrix produced by osteoblasts) was increased, as was the bone formation rate and the amount of bone estimated to be produced by each team of osteoblasts (wall width). The newly formed bone had normal lamellar architecture, as opposed to the woven bone seen in severe hyperparathyroidism (Figure 2 ).

As shown in Table 1, the number of osteoclasts was not increased by administration of PTH in either strain, indicating that neither bone resorption nor bone remodeling was increased by the $400 \mathrm{ng} / \mathrm{g} / \mathrm{d}$ dose of the hormone used in our studies. This dose was chosen on the basis of preliminary studies indicating that the effect of 80 $\mathrm{ng} / \mathrm{g} / \mathrm{d}$ on BMD in SAMR1 mice was not as strong as that of $400 \mathrm{ng} / \mathrm{g} / \mathrm{d}$ (data not shown). The latter dose is equivalent to $235 \mathrm{ng} / \mathrm{g} / \mathrm{d}$ in the rat after correction for metabolic body weight (28). Although this dose is relatively high, our findings are consistent with previous evidence that the anabolic effect of $400 \mathrm{ng} / \mathrm{g} / \mathrm{d}$ hPTH(1-34) in rats occurred without an increase in bone resorption (9).

Because osteoblasts are short-lived cells (approximately 200 hours in mice) $(4,15)$, the increase in the number of osteoblasts seen in the PTH-treated mice could be the result of either an increase in the formation of new osteoblasts or the prolongation of their life-span. Enu-
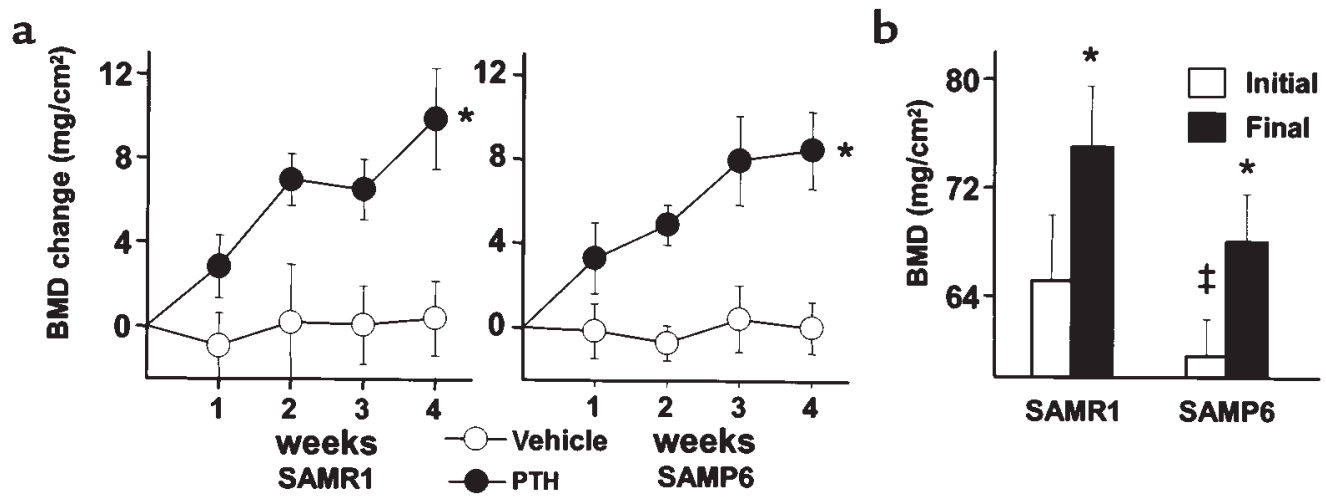

Figure 1

Effect of PTH on BMD. Mice ( $n=6-7$ per group) were given daily injections of vehicle $(0.9 \%$ saline, $0.01 \mathrm{mM} \beta$-mercaptoethanol, $0.1 \mathrm{mM}$ acetic acid) or $400 \mathrm{ng} / \mathrm{g}$ body weight of hPTH(1-34) dissolved in vehicle for 28 days. BMD was determined by dual-energy x-ray absorptiometry 1 day before initiation of the experiment (baseline scan) and at weekly intervals thereafter. (a) Mean \pm SD change in hindlimb BMD from baseline. ${ }^{*} P$ $<0.05$ vs. vehicle, established using a mixed-effects longitudinal ANOVA model to allow specification of the covariance structure. (b) Mean \pm SD BMD of hindlimb of SAMR1 and SAMP6 mice before (Initial) and after (Final) 28 days of treatment with hPTH(1-34). ${ }^{*} P<0.05$ vs. initial by paired $t$ test; $¥ P<0.05$ vs. SAMR1 by Student's $t$ test. 
Table 1

Effect of PTH on osteoblast formation, function, and fate

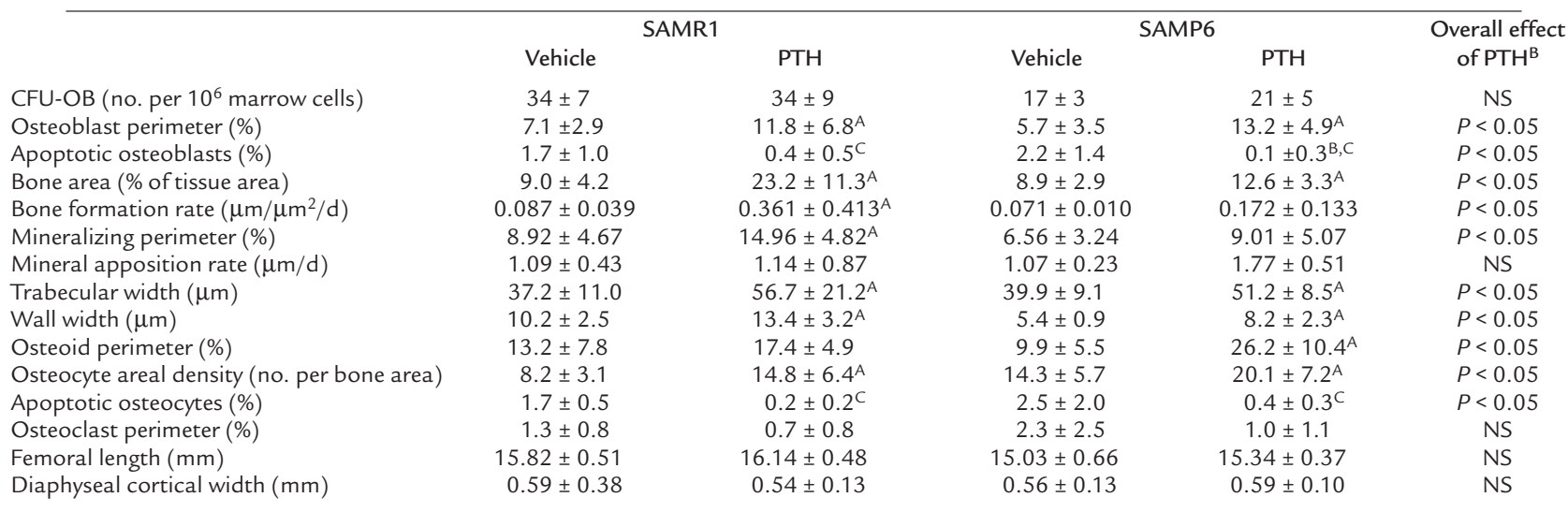

Mice from the experiment shown in Figure 1 were sacrificed on day 28 . The animals had been pretreated with tetracycline ( $5 \mu \mathrm{g} / \mathrm{g}$, subcutaneously) on days 19 and 26 . Osteoblast progenitors were measured using marrow cells from 1 femur. The average number of nucleated cells obtained from the femur of PTH-treated animals (19.8 \pm $3.2 \times 10^{6}$ from SAMR1; $24.3 \pm 3.0 \times 10^{6}$ from SAMP6) was indistinguishable from animals receiving vehicle $\left(21.0 \pm 2.7 \times 10^{6}\right.$ from SAMR1; $21.5 \pm 3.2 \times 10^{6}$ from SAMP6). The remaining femur and lumbar vertebrae were fixed and embedded undecalcified in methylmethacrylate $(3,4,15)$. Femurs were used for histomorphometric analysis, and vertebrae were used for apoptosis determinations. Because osteoblasts in remodeling bone comprise a team, they were identified as cuboidal cells in a row of at least 3 , lining the osteoid-covered trabecular perimeter. Osteocytes were identified inside lacunae of mineralized cancellous bone. For detection of apoptotic cells, sections were incubated with $\mathrm{CuSO}_{4}$ to enhance staining of the peroxidase reaction production during the TUNEL procedure, as described in Methods. Osteoblasts and osteocytes exhibiting both brown staining due to TUNEL and the morphological feature of nuclear condensation were counted as apoptotic. With these precautions, TUNEL has been unequivocally associated with apoptosis of osteoblasts and osteocytes in bone $(4,29,50)$. See Table 2 for a summary of apoptotic and nonapoptotic cell counts in individual animals. The data shown represent the mean \pm SD of each measurement determined from bones from each animal. ${ }^{A} P<0.05$ vs. vehicle by 1 -tailed Student's $t$ test. ${ }^{B}$ Two-way ANOVA was used to detect overall effects of PTH. ${ }^{C} P<0.001$ vs. vehicle by GSK categorical general linear regression (26).

meration of osteoblast progenitors in ex vivo bone marrow cell cultures, an index of de novo osteoblastogenesis (3), showed no difference between PTH- and vehicletreated animals (Table 1). The lack of effect of PTH on osteoblast progenitors was documented in the normal mouse strain (SAMR1), as well as in the strain with the diminished baseline osteoblastogenesis (SAMP6), clearly demonstrating that an increase in the formation of new osteoblasts could not account for the increased osteoblast numbers seen in both strains.

Strikingly, however, the proportion of osteoblasts undergoing apoptosis, as determined by TUNEL labeling, was greatly decreased in animals of either strain receiving PTH (Table 1 ). Table 2 shows counts of apop-
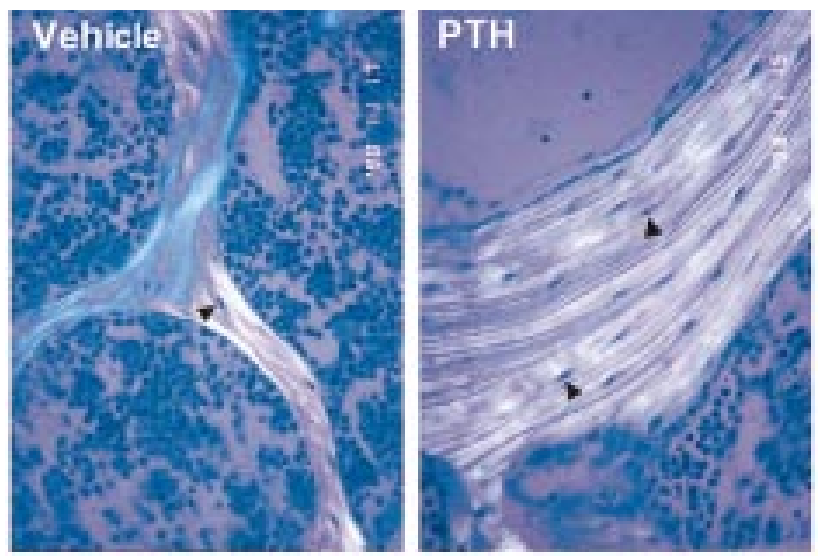

\section{Figure 2}

Distal femoral cancellous bone viewed with polarized light to reveal lamellar architecture. The increased areal density of osteocytes (arrowheads) in bone of animals receiving PTH can also be seen. $\times 200$. totic osteoblasts determined with 2 separate assays. When TUNEL was performed without $\mathrm{CuSO}_{4}$ enhancement, no apoptotic osteoblasts were detected among the 3,700 osteoblasts examined in PTH-treated SAMR1 mice, and only 1 apoptotic osteoblast was seen among the 2,200 examined in PTH-treated SAMP6 mice, whereas 5 of $1,500(0.3 \%)$ and 7 of $1,750(0.4 \%)$ were apoptotic in vehicle-treated SAMR1 and SAMP6 mice, respectively. When $\mathrm{CuSO}_{4}$ was used to enhance TUNEL labeling, the average proportion of apoptotic osteoblasts using TUNEL labeling was $0.4 \pm 0.5 \%$ in PTH-treated SAMR1, as compared with $1.7 \pm 1.0 \%$ for vehicle-treated SAMR1. Similarly, the average proportion of apoptotic osteoblasts in PTH-treated SAMP6 was $0.1 \pm 0.3 \%$, as compared with $2.2 \pm 1.4 \%$ for vehicle-treated SAMP6. The prevalence of apoptotic osteoblasts in vehicle-treated mice was lower without $\mathrm{CuSO}_{4}$ enhancement; but it is nearly identical to that seen in our previous studies in Swiss-Webster mice $(4,15)$ and by Silvestrini et al. in their study of the cancellous bone of rat tibia (29). The increase in the absolute number of TUNEL-labeled cells observed with $\mathrm{CuSO}_{4}$ enhancement is consistent with the contention that this procedure allows cells undergoing the DNA degradation phase to be seen at an earlier stage. Prolongation or shortening of the time that apoptosis can be observed in a specimen, as a result of using more- or less-sensitive detection methods, influences the prevalence of the phenomenon. This influence, and the variability of the duration of the apoptosis process in different cell types, can account for reports estimating the TUNEL-labeled phase of apoptosis from as little as 1.5 hours to as much as 48 hours $(30,31)$.

PTH-treated mice also exhibited increased osteocyte density - number per cancellous bone area (Table 1 and Figure 2). Osteocytes are former osteoblasts that have 


\section{Figure 3}

Mechanism and signal specificity of the suppressive effect of PTH on apoptosis in cultures of osteoblastic and osteocytic cells. (a) Cultures were maintained for 6 hours in the presence of $10^{-7} \mathrm{M}$ dexamethasone (Dex) without or with preincubation for 1 hour with $10^{-8} \mathrm{M} \mathrm{bPTH}(1-34)$. The pyknotic fragmented nuclei (arrows) typical of apoptotic cells were viewed using HOECHST 33258 fluorescent dye in osteoblastic calvaria cells and by EGFP fluorescence in MLO-Y4 osteocytes. $\times 400$. Insets: percentage of cells undergoing apoptosis, as determined from evaluation of nuclear morphology of 500 cells in randomly selected fields. (b) Cells $\left(10^{4} / \mathrm{cm}^{2}\right)$ were incubated for 1 hour in vehicle or $10^{-8} \mathrm{M} \mathrm{bPTH}(1-34)$, and then incubated for an additional 6 hours in the absence (basal) or presence of $5 \times 10^{-5} \mathrm{M}$ etoposide (Etop), $10^{-7} \mathrm{M}$ dexamethasone (Dex), or $10^{-9} \mathrm{MTNF}$. (c) Osteoblastic calvaria cells were cultured for 1 hour in vehicle or the indicated log molar concentrations of bPTH(1-34), bPTH(3-34), or dibutyryl cAMP (DB-cAMP), and then for an additional 6 hours in the absence or presence of $10^{-7} \mathrm{M}$ dexamethasone. Apoptotic cells in $\mathbf{b}$ and $\mathbf{c}$ were enumerated by trypan blue staining. Bars represent mean \pm SD of triplicate wells. Nearly identical results were obtained in at least 2 additional experiments. Data were analyzed by ANOVA. Etoposide, dexamethasone, and TNF caused a significant $(P<0.05)$ increase in apoptosis in cultures containing vehicle. ${ }^{*} P<0.05$ vs. vehicle (b) or vs. dexamethasone alone (c).

completed their bone-forming function and are encased within lacunae of the mineralized bone matrix, 1 of the 3 possible fates of matrix-synthesizing cells, the other 2 being apoptosis and conversion to lining cells. Hence, an increase in osteocyte density is consistent with, and can only be accounted for by, a suppression of osteoblast apoptosis. Besides the effect on osteoblast apoptosis, intermittent PTH administration also inhibited osteocyte apoptosis (Tables 1 and 2).

To determine whether the antiapoptotic effect of PTH was due to direct action of the hormone on osteoblasts and osteocytes, as opposed to indirect actions mediated by compensatory changes, the effect of PTH on apoptosis was examined using cell cultures. Addition of dexamethasone to primary cultures of osteoblasts isolated from neonatal murine calvaria, or to MLO-Y4 osteocytic cells (32), induced apoptosis, as indicated by the appearance of pyknotic nuclei (Figure 3a). Nuclear morphology was assessed by HOECHST dye staining for calvarial osteoblasts and by fluorescence for MLO-Y4 cells stably transfected with an EGFP vector containing a nuclear localization sequence. Practically identical results were obtained using TUNEL labeling to detect apoptotic cells (not shown). The proapoptotic effect of dexamethasone was attenuated by addition of $10 \mathrm{nM}$ bovine PTH(1-34) [bPTH(1-34)], regardless of whether nuclear fragmentation (Figure 3a), trypan blue staining (Figure 3b), or TUNEL labeling (not shown) was used to detect cell death. Based on experiments showing that at least $90 \%$ of trypan blue-stained cells also exhibited TUNEL labeling (not shown), subsequent studies were performed using trypan blue staining as an index of apoptosis. Figure $3 \mathrm{~b}$ shows that PTH inhibited apoptosis stimulated by etoposide or dexamethasone in cultures of calvarial osteoblasts, MLO-Y4 cells, MC3T3-E1 murine osteoblastic cells, and MG-63 human osteoblastic cells. On the other hand, induction of apoptosis by a

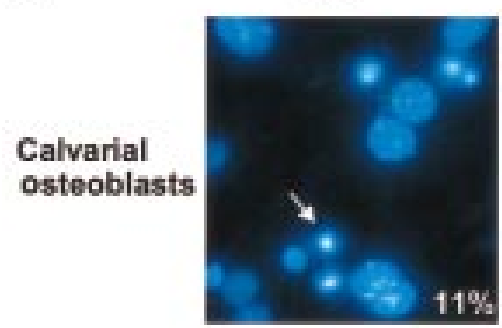

Dex+PTH

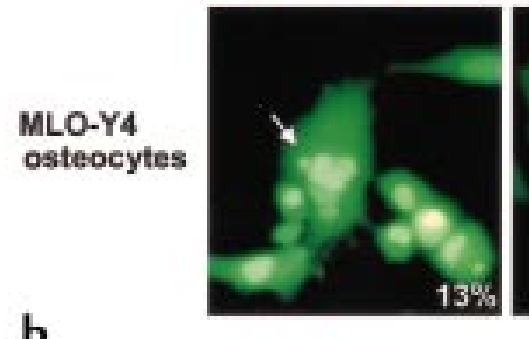

b

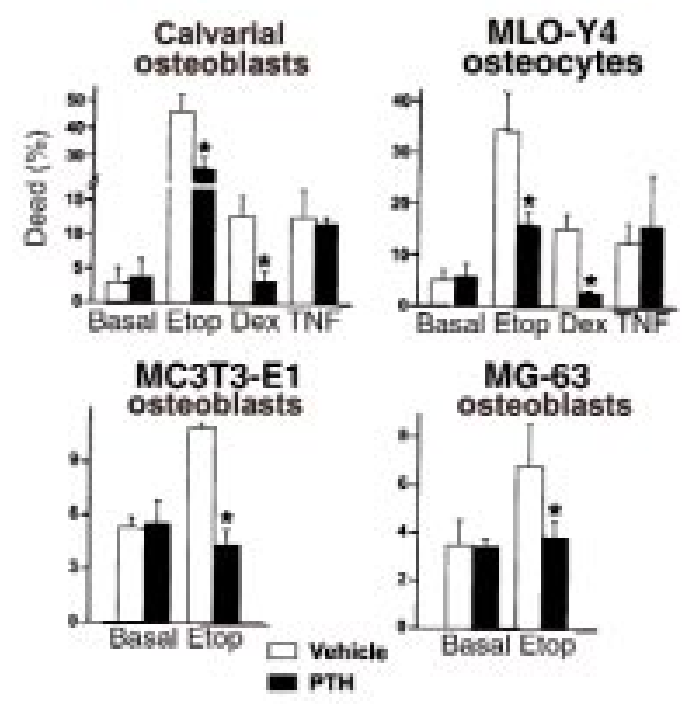

c

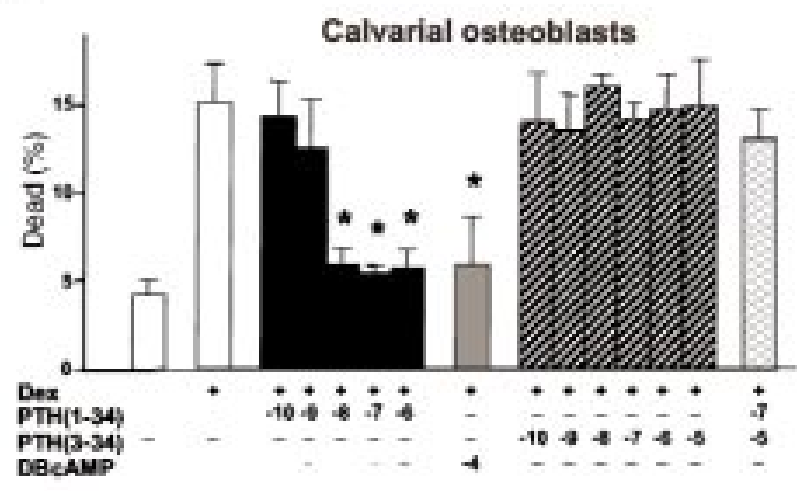

TNF was not affected by PTH. As expected, the cell-permeable inhibitor of caspases required for the execution phase of apoptosis, DEVD-CHO $(33,34)$, inhibited cell death regardless of the stimulating agent (not shown). The antiapoptotic effect of PTH could be blocked by the PTH/PTHrP receptor antagonist bPTH(3-34) and was mimicked by dibutyryl cAMP, indicating that it was mediated through the PTH/PTHrP receptor and subsequent activation of adenylate cyclase (Figure 3c). 
Table 2

Effect of PTH on apoptosis of osteoblasts and osteocytes in vertebral cancellous bone

\begin{tabular}{|c|c|c|c|c|c|c|c|}
\hline Group & $\begin{array}{l}\text { Sample, } \\
\text { or mouse ID }\end{array}$ & $\begin{array}{l}\text { Apoptotic } \\
\text { OBs }\end{array}$ & $\begin{array}{c}\text { Total } \\
\text { OBs counted }\end{array}$ & $\begin{array}{l}\text { Apoptotic } \\
\text { OBs (\%) }\end{array}$ & $\begin{array}{l}\text { Apoptotic } \\
\text { OCTs }\end{array}$ & $\begin{array}{c}\text { Total } \\
\text { OCTs counted }\end{array}$ & $\begin{array}{l}\text { Apoptotic } \\
\text { OCTs (\%) }\end{array}$ \\
\hline SAMR1, vehicle & $\begin{array}{l}\text { Pooled }\left(\mathrm{w} / \mathrm{o} \mathrm{CuSO}_{4}\right) \\
\left.\text { a (with } \mathrm{CuSO}_{4}\right) \\
\text { b } \\
\text { c } \\
\text { d } \\
\text { e } \\
\text { f }\end{array}$ & $\begin{array}{l}5 \\
5 \\
9 \\
6 \\
1 \\
1 \\
1\end{array}$ & $\begin{array}{c}1,500 \\
271 \\
280 \\
258 \\
199 \\
113 \\
69 \\
\text { Mean } \pm \text { SD: }\end{array}$ & $\begin{array}{c}0.3 \\
1.8 \\
3.2 \\
2.3 \\
0.5 \\
0.9 \\
1.4 \\
1.7 \pm 1.0\end{array}$ & $\begin{array}{l}- \\
7 \\
9 \\
4 \\
2 \\
4 \\
2\end{array}$ & $\begin{array}{c}- \\
368 \\
350 \\
240 \\
237 \\
244 \\
98\end{array}$ & $\begin{array}{c}- \\
1.9 \\
2.5 \\
1.6 \\
0.8 \\
1.6 \\
1.8 \\
1.7 \pm 0.5\end{array}$ \\
\hline SAMR1, PTH & $\begin{array}{l}\text { Pooled }\left(\mathrm{w} / \mathrm{o} \mathrm{CuSO}_{4}\right) \\
\left.\text { a (with } \mathrm{CuSO}_{4}\right) \\
\text { b } \\
\text { c } \\
\text { d } \\
\text { e } \\
\text { f }\end{array}$ & $\begin{array}{l}0 \\
0 \\
1 \\
1 \\
3 \\
2 \\
2 \\
0\end{array}$ & $\begin{array}{c}3,700 \\
206 \\
328 \\
372 \\
206 \\
397 \\
151 \\
\text { Mean } \pm \text { SD: }\end{array}$ & $\begin{array}{c}0^{\mathrm{A}} \\
0 \\
0.3 \\
0.3 \\
1.4 \\
0.5 \\
0 \\
0.4 \pm 0.5^{\mathrm{B}}\end{array}$ & $\begin{array}{l}- \\
0 \\
1 \\
2 \\
2 \\
1 \\
0\end{array}$ & $\begin{array}{c}- \\
403 \\
477 \\
489 \\
618 \\
669 \\
262\end{array}$ & $\begin{array}{c}- \\
0 \\
0.3 \\
0.3 \\
1.4 \\
0.5 \\
0 \\
0.2 \pm 0.2^{\mathrm{B}}\end{array}$ \\
\hline SAMP6, vehicle & $\begin{array}{l}\text { Pooled }\left(\mathrm{w} / \mathrm{o} \mathrm{CuSO}_{4}\right) \\
\left.\text { a (with } \mathrm{CuSO}_{4}\right) \\
\text { b } \\
\text { c } \\
\text { d } \\
\text { e } \\
\text { f } \\
\text { g }\end{array}$ & $\begin{array}{l}7 \\
6 \\
3 \\
1 \\
3 \\
2 \\
1 \\
2\end{array}$ & $\begin{array}{c}1,750 \\
180 \\
64 \\
114 \\
185 \\
109 \\
88 \\
113 \\
\text { Mean } \pm \text { SD: }\end{array}$ & $\begin{array}{c}0.4 \\
3.4 \\
4.7 \\
0.9 \\
1.6 \\
1.8 \\
1.1 \\
1.8 \\
2.2 \pm 1.4\end{array}$ & $\begin{array}{c}- \\
9 \\
4 \\
10 \\
1 \\
9 \\
1 \\
11\end{array}$ & $\begin{array}{l}- \\
204 \\
302 \\
169 \\
353 \\
342 \\
208 \\
384\end{array}$ & $\begin{array}{c}- \\
4.3 \\
1.3 \\
5.7 \\
0.3 \\
2.6 \\
0.5 \\
2.8 \\
2.5 \pm 2.0\end{array}$ \\
\hline SAMP6, PTH & $\begin{array}{l}\text { Pooled }\left(\mathrm{w} / \mathrm{o} \mathrm{CuSO}_{4}\right) \\
\left.\text { a (with } \mathrm{CuSO}_{4}\right) \\
\text { b } \\
\text { c } \\
\text { d } \\
\text { e } \\
\text { f }\end{array}$ & $\begin{array}{l}1 \\
0 \\
0 \\
3 \\
0 \\
0 \\
0\end{array}$ & $\begin{array}{c}2,200 \\
289 \\
387 \\
400 \\
160 \\
120 \\
134 \\
\text { Mean } \pm \text { SD: }\end{array}$ & $\begin{array}{c}0.05^{\mathrm{A}} \\
0 \\
0 \\
0.8 \\
0 \\
0 \\
0 \\
0.1 \pm 0.3^{\mathrm{B}}\end{array}$ & $\begin{array}{l}- \\
3 \\
1 \\
2 \\
2 \\
2 \\
1 \\
0\end{array}$ & $\begin{array}{c}- \\
500 \\
487 \\
350 \\
321 \\
293 \\
303\end{array}$ & $\begin{array}{c}- \\
0.6 \\
0.2 \\
0.7 \\
0.6 \\
0.3 \\
0 \\
0.4 \pm 0.3^{\mathrm{B}}\end{array}$ \\
\hline
\end{tabular}

Osteoblasts (OBs) and osteocytes (OCTs) were identified in sections of lumbar vertebrae, and those exhibiting both brown staining due to TUNEL and pyknotic nuclei were counted as apoptotic, as described in Table 1. Results from 2 separate TUNEL-staining procedures are shown. In the first, TUNEL was performed without CuSO enhancement ( $\left.\mathrm{w} / \mathrm{o} \mathrm{CuSO}_{4}\right)$, and data were pooled from animals from each group for statistical analysis because of the low number of apoptotic osteoblasts seen with this method. In the second, $\mathrm{CuSO}_{4}$ (with $\mathrm{CuSO}_{4}$ ) was used to enhance TUNEL staining, and counts from each animal are shown. With the exception of the apoptotic osteocyte counts in the vehicle-treated SAMP6 group, there were no significant differences among the animals within each group. Pooled data $\left(\mathrm{w} / \mathrm{o} \mathrm{CuSO}_{4}\right)$ were analyzed by logistic regression. ${ }^{A} P<0.0001$ vs. vehicle. Data from individual animals were analyzed by GSK as described in Methods. ${ }^{B} P<0.001$ vs. vehicle.

\section{Discussion}

The data presented in this report indicate that intermittent administration of PTH stimulates bone formation not by increasing the proliferation of osteoblast precursors, but by preventing osteoblast apoptosis the fate of the majority of these cells under normal conditions $(4,15)$ - thereby prolonging the time spent in performing their matrix-synthesizing function. The antiapoptotic effect of PTH is exerted directly on osteoblasts; requires binding of the hormone to the $\mathrm{PTH} / \mathrm{PTHrP}$ receptor; is mediated by cAMP-generated signals that interfere with some, but not all, death pathways; and occurs upstream of the common executing phase of apoptosis. Consistent with the results of the present studies in mice, the ability of intermittent administration of PTH to increase osteoblast numbers was not accompanied by an increase in the replication of osteoblast progenitors in the rat (35). Moreover, the demonstration of the ability of PTH to inhibit osteoblast apoptosis is in full agreement with the antiapoptotic effect of PTHrP on chondrocytes during endochondral bone development $(36,37)$. A cAMP-mediated inhibition of osteoblast apoptosis by
PTH should be a rapid event; but the increase in bone mass is most likely the cumulative result of the repeated daily postponement of apoptosis over several generations of osteoblasts. Whether the observed prolongation of the life-span of osteocytes - the putative mechanosensors and most abundant cell type in bone (38) - contributes to the anabolic effect of PTH is an intriguing, but as yet unproven, possibility.

Several lines of evidence support the notion that the antiapoptotic effect of PTH on osteoblasts is mediated by cAMP. Indeed, Machwate et al. (39) showed that periosteal cell apoptosis was inhibited by prostaglandin E through cAMP-dependent stimulation of sphingosine kinase. Moreover, whereas the $G$ protein-coupled receptor for PTH stimulated apoptosis in cells expressing Gq (an activator of JNK and calcium signaling), PTH inhibited apoptosis in cells expressing Gs, an activator of adenylate cyclase (40). Because osteoblastic cells uniformly produce cAMP in response to PTH, it is highly likely that the Gs-mediated antiapoptotic effect of PTH dominates in this cell type, exactly as we found in each of the osteoblastic cell preparations examined in the in vitro studies presented in this report. 
Results from a recent clinical study showed that daily subcutaneous injection of PTH is an effective treatment for glucocorticoid-induced osteoporosis (11). The decreased bone formation rate and wall thickness of trabeculae - indicators of diminished work by osteoblasts and the in situ death of portions of bone that characterize glucocorticoid-induced osteoporosis - can be accounted for by a suppressive effect of glucocorticoids on osteoblastogenesis and promotion of apoptosis of osteoblasts and osteocytes (4). The elucidation of the antiapoptotic effects of PTH in vivo, and the evidence that PTH antagonizes the proapoptotic effects of glucocorticoids in vitro, are in full agreement with these clinical observations. Furthermore, they provide a mechanistic explanation for the efficacy of PTH in glucocorticoid-induced osteoporosis, as well as compelling evidence that its antiapoptotic properties make PTH a rational pharmacotherapeutic choice for this condition.

Previous in vivo and in vitro studies have suggested that PTH can stimulate the replication of osteoblast progenitors (41-43). However, the equivalent anabolic response of normal SAMR1 and SAMP6 mice with defective osteoblastogenesis to daily injections of hPTH(1-34), together with the failure to observe a stimulatory effect of the hormone on the number of osteoblast progenitors obtained from the marrow of either strain, strongly suggests that the anabolic effect of PTH is not dependent on increased osteoblastogenesis. Apart from decreased cell death, another potential source of new osteoblasts is the lining cells that cover quiescent bone surfaces (44). These cells were once matrix-synthesizing osteoblasts, and have escaped apoptosis or encasement within bone as osteocytes to remain on the bone surface. It has been suggested that PTH can stimulate lining cells to undergo hypertrophy and to resume matrix synthesis $(35,45)$. However, in the present study there was no change in lining cell morphology, which is quite distinct from that of osteoblasts (44). In any event, such conversion would be insufficient to cover the expanded cancellous bone perimeter and to account for the increased osteocyte number and density we observed. These considerations do not eliminate the possibility that PTH activates lining cells in the early phase of treatment or stimulates the differentiation of osteoblast progenitors that are beyond the $\mathrm{CFU}-\mathrm{OB}$ stage we examined in this study. Hence, additional experiments are needed to prove whether inhibition of osteoblast apoptosis by PTH is the sole mechanism responsible for the anabolic effect of the hormone.

In conclusion, the findings of this report indicate that prevention of osteoblast apoptosis is a crucial mechanism for the anabolic effects of PTH on bone. The demonstration of increasing work output of a cell population by suppressing apoptosis to augment tissue mass provides proof of the principle for regenerating tissues in general, and paves the way for the development of new pharmacotherapeutic strategies.

\section{Acknowledgments}

The authors thank S.M. Krane and B.F. Boyce for their helpful critiques during the preparation of the manuscript, and F. Swain, J. Crawford, R. Shelton, T. Chambers, S. Rush, L. Plotkin, L. Han, and C. Smith for their technical assistance. This work was support by NIH grants (PO1-AG13918 and RO1-AR 43003) and the Department of Veterans Affairs.

1. Manolagas, S.C., and Jilka, R.L. 1995. Mechanisms of disease: bone marrow, cytokines, and bone remodeling. Emerging insights into the pathophysiology of osteoporosis. N. Engl. J. Med. 332:305-311.

2. Jilka, R.L., et al. 1992. Increased osteoclast development after estrogen loss: mediation by interleukin-6. Science. 257:88-91.

3. Jilka, R.L., Weinstein, R.S., Takahashi, K., Parfitt, A.M., and Manolagas, S.C. 1996. Linkage of decreased bone mass with impaired osteoblastogenesis in a murine model of accelerated senescence. J. Clin. Invest. 97:1732-1740.

4. Weinstein, R.S., Jilka, R.L., Parfitt, A.M., and Manolagas, S.C. 1998. Inhibition of osteoblastogenesis and promotion of apoptosis of osteoblasts and osteocytes by glucocorticoids: potential mechanisms of their deleterious effects on bone. J. Clin. Invest. 102:274-282.

5. Dempster, D.W., Cosman, F., Parisien, M., and Shen, V. 1993. Anabolic actions of parathyroid hormone on bone. Endocr. Rev. 14:690-709.

6. Reeve, J., et al. 1976. Anabolic effect of low doses of a fragment of human parathyroid hormone on the skeleton in postmenopausal osteoporosis. Lancet. 1:1035-1038.

7. Reeve, J., et al. 1980. Anabolic effect of human parathyroid hormone fragment on trabecular bone in involutional osteoporosis: a multicentre trial. Br. Med. J. 280:1340-1344.

8. Tam, C.S., Heersche, J.N.M., Murray, T.M., and Parsons, J.A. 1982. Parathyroid hormone stimulates the bone apposition rate independently of its resorptive action: differential effects of intermittent and continuous administration. Endocrinology. 110:506-512.

9. Lane, N.E., et al. 1996. Bone-selective analogs of human PTH(1-34) increase bone formation in an ovariectomized rat model. J. Bone Miner. Res. 11:614-625.

10. Finkelstein, J.S., et al. 1998. Prevention of estrogen deficiency-related bone loss with human parathyroid hormone-(1-34): a randomized controlled trial. JAMA. 280:1067-1073.

11. Lane, N.E., et al. 1998. Parathyroid hormone treatment can reverse corticosteroid-induced osteoporosis. J. Clin. Invest. 102:1627-1633.

12. Stewart, A.F. 1996. PTHrP(1-36) as a skeletal anabolic agent for the treatment of osteoporosis. Bone. 19:303-306.

13. Vickery, B.H., et al. 1996. RS-66271, a C-terminally substituted analog of human parathyroid hormone-related protein (1-34), increases trabecular and cortical bone in ovariectomized, osteopenic rats. J. Bone Miner. Res. 11:1943-1951.

14. Parfitt, A.M. 1990. Bone-forming cells in clinical conditions. In Bone. Volume 1: the osteoblast and osteocyte. B.K. Hall, editor. Telford Press and CRC Press. Boca Raton, FL. 351-429.

15. Jilka, R.L., Weinstein, R.S., Bellido, T., Parfitt, A.M., and Manolagas, S.C. 1998. Osteoblast programmed cell death (apoptosis): modulation by growth factors and cytokines. J. Bone Miner. Res. 13:793-802.

16. Jilka, R.L., et al. 1998. Loss of estrogen upregulates osteoblastogenesis in the murine bone marrow: evidence for autonomy from factors released during bone resorption. J. Clin. Invest. 101:1942-1950.

17. Aubin, J.E. 1998. Bone stem cells. J. Cell. Biochem. Suppl. 30-31:73-82.

18. Weinstein, R.S., Jilka, R.L., Parfitt, A.M., and Manolagas, S.C. 1997. The effects of androgen deficiency on murine bone remodeling and bone mineral density are mediated via cells of the osteoblastic lineage. Endocrinology. 138:4013-4021.

19. Parfitt, A.M., et al. 1987. Bone histomorphometry: standardization of nomenclature, symbols, and units. Report of the ASBMR Histomorphometry Nomenclature Committee. J. Bone Miner. Res. 2:595-610.

20. Villanueva, A.R., Sypitkowski, C., and Parfitt, A.M. 1986. A new method for identification of cement lines in undecalcified, plastic embedded sections of bone. Stain Technol. 61:83-88.

21. Hsu, S.M., and Soban, E. 1982. Color modification of diaminobenzidine (DAB) precipitation by metallic ions and its application for double immunohistochemistry. J. Histochem. Cytochem. 30:1079-1082.

22. Short, B.G., Zimmerman, D.M., and Schwartz, L.W. 1997. Automated double labeling of proliferation and apoptosis in glutathione S-transferase-positive hepatocytes in rats. J. Histochem. Cytochem. 45:1299-1305.

23. Jilka, R.L. 1986. Parathyroid hormone-stimulated development of osteoclasts in cultures of cells from neonatal murine calvaria. Bone. 7:29-40.

24. Kalderon, D., Roberts, B.L., Richardson, W.D., and Smith, A.E. 1984. A short amino acid sequence able to specify nuclear location. Cell. 39:499-509.

25. Perry, S.W., Epstein, L.G., and Gelbard, H.A. 1997. Simultaneous in situ detection of apoptosis and necrosis in monolayer cultures by TUNEL and trypan blue staining. Biotechniques. 22:1102-1106.

26. Freeman, D.H., Jr. 1987. Multiple-factor models: GSK methods. In Applied categorical data analysis. Volume 79. D.B. Owen and R.G. Cornell, editors. Marcel Dekker Inc. New York, NY. 179-207.

27. Freeman, D.H., Jr. 1987. Univariate analysis. In Applied categorical data 
analysis. Volume 79. D.B. Owen and R.G. Cornell, editors. Marcel Dekker Inc. New York, NY. 11-54.

28. Kleiber, M. 1961. The fire of life: an introduction to animal energetics. John Wiley \& Sons. New York, NY. 177-230.

29. Silvestrini, G., Mocetti, P., Ballanti, P., Di Grezia, R., and Bonucci, E. 1998. In vivo incidence of apoptosis evaluated with the TdT FragEL(TM) DNA fragmentation detection kit in cartilage and bone cells of the rat tibia. Tissue Cell. 30:627-633.

30. Bursch, W., Paffe, S., Putz, B., Barthel, G., and Schulte-Hermann, R. 1990. Determination of the length of the histological stages of apoptosis in normal liver and in altered hepatic foci of rats. Carcinogenesis. 11:847-853.

31. Pompeiano, M., Hvala, M., and Chun, J. 1998. Onset of apoptotic DNA fragmentation can precede cell elimination by days in the small intestinal villus. Cell Death Differ. 5:702-709.

32. Kato, Y., Windle, J.J., Koop, B.A., Mundy, G.R., and Bonewald, L.F. 1997. Establishment of an osteocyte-like cell line, MLO-Y4. J. Bone Miner. Res. 12:2014-2023.

33. Thornberry, N.A., and Lazebnik, Y. 1998. Caspases: enemies within. Science. 281:1312-1316.

34. Wright, S.C., et al. 1997. Activation of CPP32-like proteases is not sufficient to trigger apoptosis: inhibition of apoptosis by agents that suppress activation of AP24, but not CPP32-like activity. J. Exp. Med. 186:1107-1117.

35. Dobnig, H., and Turner, R.T. 1995. Evidence that intermittent treatment with parathyroid hormone increases bone formation in adult rats by activation of bone lining cells. Endocrinology. 136:3632-3638.

36. Amling, M., et al. 1997. Bcl-2 lies downstream of parathyroid hormonerelated peptide in a signaling pathway that regulates chondrocyte maturation during skeletal development. J. Cell Biol. 136:205-213.

37. Lee, K., et al. 1996. Parathyroid hormone-related peptide delays termi- nal differentiation of chondrocytes during endochondral bone development. Endocrinology. 137:5109-5118.

38. Aarden, E.M., Burger, E.H., and Nijweide, P.J. 1994. Function of osteocytes in bone. J. Cell. Biochem. 55:287-299.

39. Machwate, M., Rodan, S.B., Rodan, G.A., and Harada, S.I. 1998. Sphingosine kinase mediates cyclic AMP suppression of apoptosis in rat periosteal cells. Mol. Pharmacol. 54:70-77.

40. Turner, P.R., Bencsik, M., Malecz, N., Christakos, S., and Nissenson, R.A. 1998. Apoptosis mediated by the PTH/PTHrP receptor: role of JNK and calcium signaling pathways. Bone. 23:S155. (Abstr.)

41. Nishida, S., et al. 1994. Increased bone formation by intermittent parathyroid hormone administration is due to the stimulation of proliferation and differentiation of osteoprogenitor cells in bone marrow. Bone. 15:717-723.

42. MacDonald, B.R., Gallagher, J.A., and Russell, R.G. 1986. Parathyroid hormone stimulates the proliferation of cells derived from human bone. Endocrinology. 118:2445-2449.

43. Onishi, T., Zhang, W.Y., Cao, X., and Hruska, K. 1997. The mitogenic effect of parathyroid hormone is associated with E2F-dependent activation of cyclin-dependent kinase 1 (cdc2) in osteoblast precursors. J. Bone Miner. Res. 12:1596-1605.

44. Miller, S.C., and Jee, W.S.S. 1992. Bone lining cells. In Bone: bone metabolism and mineralization. Volume 4. B.K. Hall, editor. CRC Press. Boca Raton, FL. 1-19.

45. Leaffer, D., et al. 1995. Modulation of osteogenic cell ultrastructure by RS-23581, an analog of human parathyroid hormone (PTH)-related peptide-(1-34), and bovine PTH-(1-34). Endocrinology. 136:3624-3631.

46. Tomkinson, A., Gevers, E.F., Wit, J.M., Reeve, J., and Noble, B.S. 1998. The role of estrogen in the control of rat osteocyte apoptosis. J. Bone Miner. Res. 13:1243-1250. 